\title{
Involvement of the lateral septal area in the expression of fear conditioning to context
}

\author{
Daniel G. Reis, América A. Scopinho, Francisco S. Guimarães, Fernando M.A. Corrêa, and \\ Leonardo B.M. Resstel ${ }^{1}$
}

Department of Pharmacology, School of Medicine of Ribeirão Preto, University of São Paulo, Ribeirão Preto, 14049-900 São Paulo, Brazil

\begin{abstract}
Considering the evidence that the lateral septal area (LSA) modulates defensive responses, the aim of the present study is to verify if this structure is also involved in contextual fear conditioning responses. Neurotransmission in the LSA was reversibly inhibited by bilateral microinjections of cobalt chloride $\left(\mathrm{CoCl}_{2}, 1 \mathrm{mM}\right) 10 \mathrm{~min}$ before or after conditioning or 10 min before re-exposure to the aversively conditioned chamber. Only those animals that received $\mathrm{CoCl}_{2}$ before re-exposure showed a decrease in both cardiovascular and behavioral conditioned responses. These results suggest that the LSA participates in the expression, but not acquisition or consolidation, of contextual fear conditioning.
\end{abstract}

The lateral septal area (LSA) has been related to the modulation of several cognitive and emotional processes including learning, memory, anxiety, and regulation of autonomic responses (Covian 1966; Paxinos 1995; Sheehan et al. 2004; Scopinho et al. 2006, 2007). This structure is activated during aversive situations (Pezzone et al. 1992; Duncan et al. 1993; Beck and Fibiger 1995; Kubo et al. 2002) and sends projections to brain regions involved in the behavioral and cardiovascular responses to aversive stimuli (LeDoux et al. 1988; Resstel et al. 2006a, 2008a,c; Tavares and Correa 2006; Tavares et al. 2009). There is evidence that the LSA modulates the autonomic responses to stress and emotional threat situations (Kubo et al. 2002). Also, the anxiolytic-like effect evoked by systemic administration of diazepam in rats submitted to fear conditioning to context is associated with a decrease in LSA neuronal activity (Beck and Fibiger 1995). Taken together, these data support a possible regulatory role of the LSA on behavioral and cardiovascular responses associated with aversive situations such as fear conditioning.

Conditioned fear to context is evoked by re-exposing an animal to an environment (context) that has been previously paired with an aversive or unpleasant stimulus (Blanchard and Blanchard 1969; Fanselow 1980, 2000; Resstel et al. 2006b). This re-exposure causes freezing immobility and increases in mean arterial pressure (MAP) and heart rate (HR) (Fanselow 1980; LeDoux et al. 1988; Resstel et al. 2008a,b). These responses are modulated by structures connected with the LSA, such as the medial prefrontal cortex, amygdala, and bed nucleus of the stria terminalis (Swanson and Cowan 1977; Risold and Swanson 1997; Kuniecki et al. 2002; Vertes 2004; Resstel et al. 2008a,b). Therefore, the LSA could be part of the brain circuitry involved in contextual fear conditioning. However, the precise role of the LSA in contextual fear conditioning is still not completely understood, with contradictory evidence found in the literature. For example, freezing behavior elicited by an aversively conditioned context was reported to be potentiated in rats with LSA lesion (Sparks and LeDoux 1995), whereas a recent study showed that LSA reversible inhibition by lidocaine before the conditioning

\footnotetext{
${ }^{1}$ Corresponding author.
}

E-mail leoresstel@yahoo.com.br; fax 55-16-36332301.

Article is online at http://www.learnmem.org/cgi/doi/10.1101//m.1534710. session reduces freezing (Calandreau et al. 2007). Since the former study employed irreversible LSA lesions that could have, in addition to acquisition, also influenced consolidation, retrieval, or expression of the aversive memory, differences in the experimental protocols could be responsible for the contradictory results.

Therefore, the aim of the present study was to investigate the role of the LSA in the acquisition, consolidation, and retrieval of contextual fear memory by measuring the behavioral and cardiovascular responses evoked by re-exposure to an aversively conditioned context. To accomplish that, the nonselective neurotransmission blocker cobalt chloride $\left(\mathrm{CoCl}_{2}\right)$ (Hagiwara and Byerly 1981; Lomber 1999) was microinjected into the LSA at the above-mentioned specific phases of the experimental procedure.

Male Wistar rats weighing 230-250 g were used. The animals were kept in the animal care unit of the Department of Pharmacology, School of Medicine of Ribeirão Preto, University of São Paulo, Brazil. The rats were housed individually in plastic cages with free access to food and water under a 12-h light/dark cycle (lights on at $06.30 \mathrm{~h}$ ). The institution's Animal Ethics Committee approved the housing conditions and experimental protocols.

Seven days before the experiment, the rats were anesthetized with 2,2,2-tribromoethanol ( $250 \mathrm{~g} / \mathrm{kg}$ intraperitoneally; Sigma). After scalp anesthesia with $2 \%$ lidocaine, the skull was surgically exposed, and stainless steel guide cannulae $(0.55 \mathrm{~mm})$ were implanted bilaterally into the LSA using a stereotaxic apparatus (Stoelting), as described by Scopinho et al. (2007).

Preconditioning, conditioning, and testing were carried out in a $25 \times 22 \times 22$-cm footshock box. The box had a grid floor composed of 18 stainless steel rods ( $2 \mathrm{~mm}$ in diameter), spaced $1.5 \mathrm{~cm}$ apart and wired to a shock generator (Automatic Reflex Conditioner, model 8572; Ugo Basile). The experimental box was cleaned with $70 \%$ ethanol before and after use. Preconditioning started 1 wk after guide cannula implantation and consisted of one 10-min-long pre-exposure (habituation) in the footshock box. In the conditioning shock session, performed $24 \mathrm{~h}$ after the habituation session, animals were divided into two experimental groups: nonconditioned and conditioned groups. The conditioned group was re-exposed to the footshock chamber, and, after $3 \mathrm{~min}$ of habituation, the animals were submitted to a 
A

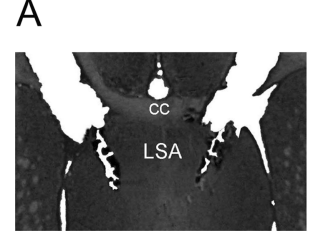

B
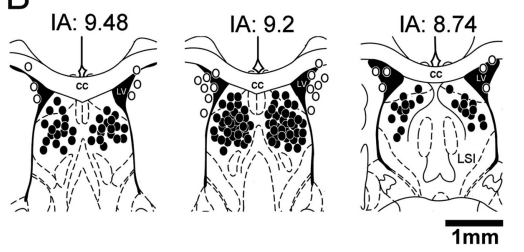

Figure 1. (A) Photomicrograph of a coronal brain section showing bilateral microinjection sites in the lateral septal area (LSA). (B) Diagrammatic representation based on the rat brain atlas of Paxinos and Watson (1997) indicating injections sites of vehicle or $\mathrm{CoCl}_{2}$ inside $(\bullet)$ or outside $(O)$ the lateral septal area (LSA). (IA) Interaural; (cc) corpus callosum; (LV) lateral ventricle.

shock session consisting of six 1.5-mA/3-sec electrical footshocks (Resstel et al. 2008a,b,c) delivered at 20-sec-1-min intervals. The nonconditioned group was re-exposed to the same footshock chamber for $10 \mathrm{~min}$, but no shock was given. To verify if the pre-exposure procedure could have influenced the results, an additional experiment was performed using a similar protocol but without pre-exposure to the conditioning chamber.

After the conditioning session, the rats had a catheter $(4-\mathrm{cm}$ PE-10 segment heat-bound to a 13-cm PE-50 segment; Clay Adams) inserted into the abdominal aorta through the femoral artery for blood pressure recording as described by Resstel et al. (2008a,d). The cardiovascular and behavioral (freezing) changes evoked by the conditioned emotional response to context were evaluated $1 \mathrm{~d}$ after femoral catheter implantation. The test session consisted of a 10-min-long re-exposure to the footshock chamber without shock delivery as described by Resstel et al. (2008d). Nonconditioned and conditioned animals received bilateral microinjection into the LSA of either $100 \mathrm{~nL}$ of vehicle (sterile artificial cerebrospinal fluid [aCSF], composition: $100 \mathrm{mM} \mathrm{NaCl}, 2 \mathrm{mM} \mathrm{Na} \mathrm{PO}_{4}, 2.5 \mathrm{mM} \mathrm{KCl}, 1 \mathrm{mM} \mathrm{MgCl}$, $27 \mathrm{mM} \mathrm{NaHCO}, 2.5 \mathrm{mM} \mathrm{CaCl}_{2} ; \mathrm{pH} 7.4$ ) or $1 \mathrm{mmol}$ of $\mathrm{CoCl}_{2}$ (Sigma) (Scopinho et al. 2007). A 0.3-mm needle (Small Parts), $1 \mathrm{~mm}$ longer than the guide cannula, connected to a $2-\mu \mathrm{L}$ syringe (7001 KH; Hamilton Co.) through a PE-10 tubing, was used for this purpose. The needles were carefully inserted into the guide cannulae, and the solutions were infused over a 15 -sec period. They remained in place for an additional 30-sec period to prevent reflux. The first group of animals received the microinjections into the LSA 10 min before the conditioning session. The second group received the microinjections into the LSA $10 \mathrm{~min}$ after the end of conditioning session. Finally, the third group received the microinjections into the LSA $10 \mathrm{~min}$ before the test session. In all animals, the cardiovascular as well as behavioral responses were recorded during the test chamber re-exposition.
At the end of the experiments the rats were sacrificed under deep anesthesia to injection site determination as described by Scopinho et al. (2007). A representative photomicrograph and a diagrammatic representation indicating the injection sites in the LSA can be seen in Figure 1.

There was a significant interaction between condition, group, and treatment $\left(F_{(2,69)}=13.7, P<0.001\right)$. Exposure to the aversive context increased freezing in vehicle-treated conditioned animals compared to the nonconditioned groups. Intra-LSA injection of $\mathrm{CoCl}_{2}$ failed to change this effect when administered immediately before or after the conditioning session. However, this treatment induced a significant decrease in freezing when administered before the test session (Bonferroni's test, $P<0.05$; Fig. 2). $\mathrm{CoCl}_{2}$ treatment did not change motor activity (number of crossing, $F_{(1,17)}=1.5, P>0.05$; rearings, $F_{(1,17)}=1.1, P>$ $0.05)$ in nonconditioned animals. Pre-exposure to the conditioning chamber did not change the effects of $\mathrm{CoCl}_{2}$ on the expression of contextual fear conditioning (data not shown).

No significant difference was found in baseline values of MAP and HR of conditioned and nonconditioned groups of animals (MAP: $F_{(11,57)}=0.75, P>0.05 ; \mathrm{HR}: F_{(11,57)}=1.7, P>$ $0.05)$. Similar to the behavioral responses, there was a significant interaction between condition, group, treatment, and time (MAP: $F_{(45,69)}=2.5, P<0.05$; HR: $\left.F_{(45,69)}=2.7, P<0.05\right)$. The administration of $\mathrm{CoCl}_{2}$ had no effect on cardiovascular responses observed during the chamber re-exposition in nonconditioned animals before conditioning (MAP: $F_{(1,135)}=1.6, P>0.05$; HR: $\left.F_{(1,135)}=0.14, P>0.05\right)$, after conditioning (MAP: $F_{(1,120)}=0.66$, $P>0.05$; HR: $\left.F_{(1,120)}=0.03, P>0.05\right)$, or before the test (MAP: $F_{(1,135)}=0.2, P>0.05$; HR: $F_{(1,135)}=1, P>0.05$; Fig. 3$)$. Compared with the vehicle-treated group, injection of $\mathrm{CoCl}_{2}$ in conditioned animals before or after conditioning did not change the increases in $\operatorname{MAP}\left(F_{(1,150)}=0.2, P>0.05\right.$ and $F_{(1,135)}=1, P>0.05$, respectively) and $\operatorname{HR}\left(F_{(1,150)}=0.2, P>0.05\right.$ and $F_{(1,135)}=1, P>0.05$, respectively) (Fig. 3). When administered before the test, however, $\mathrm{CoCl}_{2}$ attenuated the increases in both MAP and HR induced by re-exposure to the context (MAP: $F_{(1,180)}=137, P<$ 0.001; HR: $\left.F_{(1,180)}=89, P<0.001\right)$ (Fig. 3).

Acquisition of contextual conditioned fear relates to the initial learning process that occurs when an aversive unconditioned stimulus (e.g., footshock) is associated with a specific context in the training session. This is followed by a memory consolidation phase. Subsequent re-exposure to the aversive context induces a retrieval of the conditioned memory, reflected by the expression of the conditioned fear responses (Fanselow 2000). Acute neurotransmission inhibition in the LSA by local injection of $\mathrm{CoCl}_{2}$ before the test session reduced both freezing and cardiovascular responses observed during chamber re-exposure of the conditioned group. However, when $\mathrm{CoCl}_{2}$ was injected $10 \mathrm{~min}$
Before conditioning

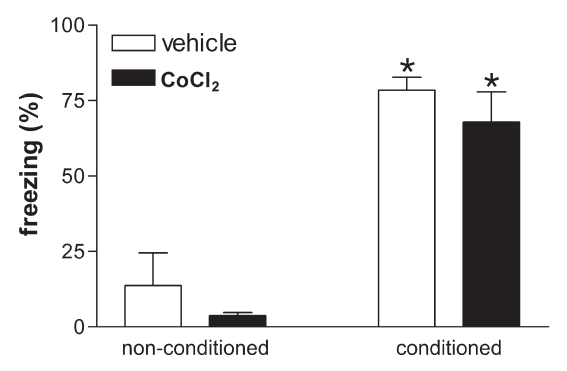

After conditioning

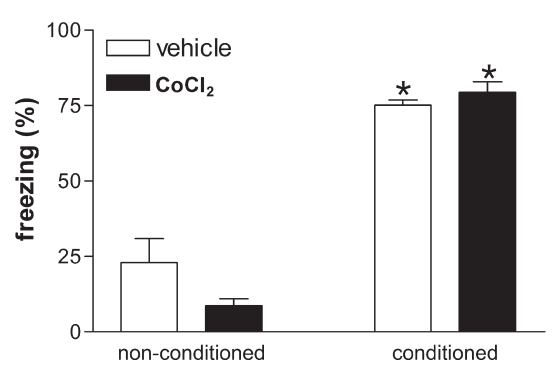

Before test

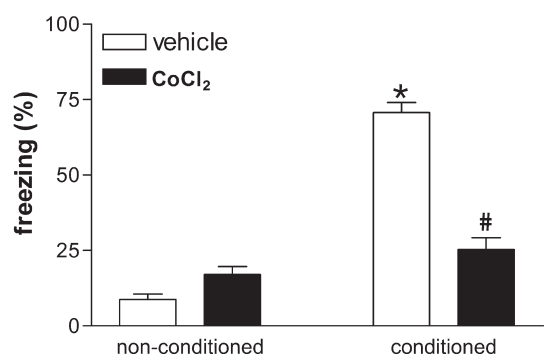

Figure 2. Effects of bilateral microinjection of $100 \mathrm{~nL}$ of vehicle or $1 \mathrm{mmol}$ of $\mathrm{CoCl}_{2}$ performed at three different treatment periods on the percentage of time spent in freezing behavior in nonconditioned $(n=5-6)$ and conditioned animals $(n=5-7)$. Columns represent the means, and bars the SEM; $\left({ }^{*}\right)$ $P<0.05$ compared to vehicle nonconditioned group; (\#) $P<0.05$ compared to vehicle conditioned group, Bonferroni's post-hoc test. 
Before Conditioning
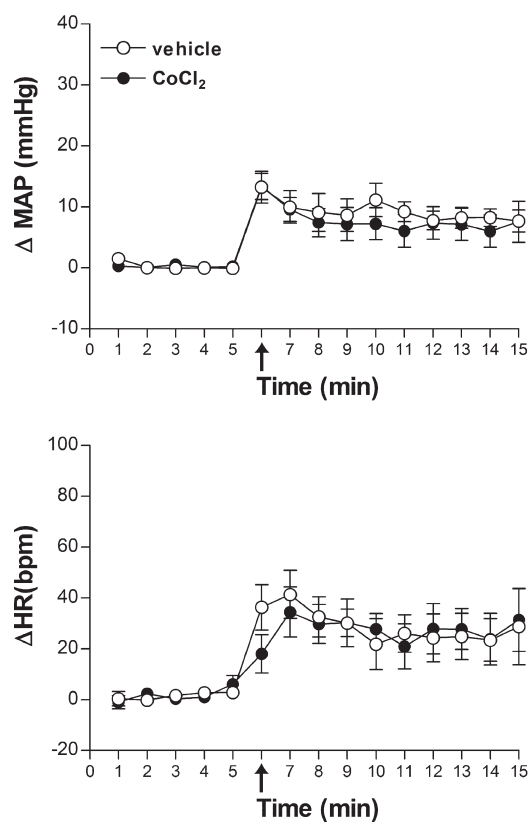

Before conditioning
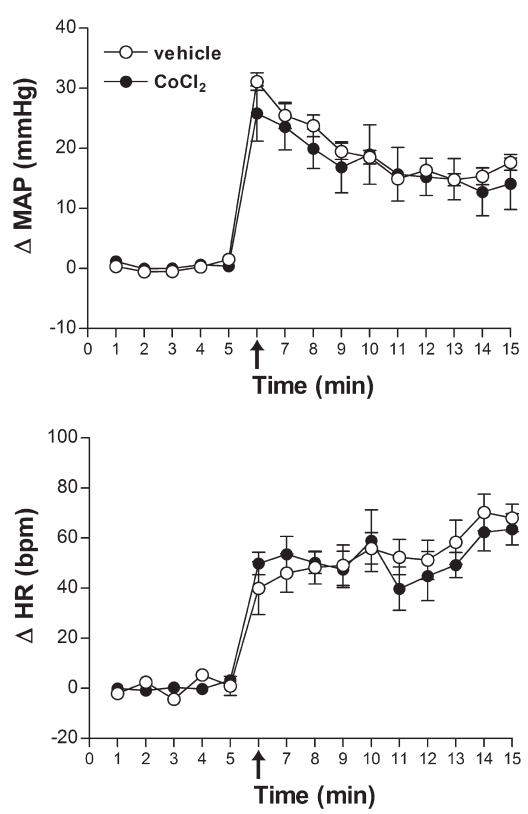

After Conditioning
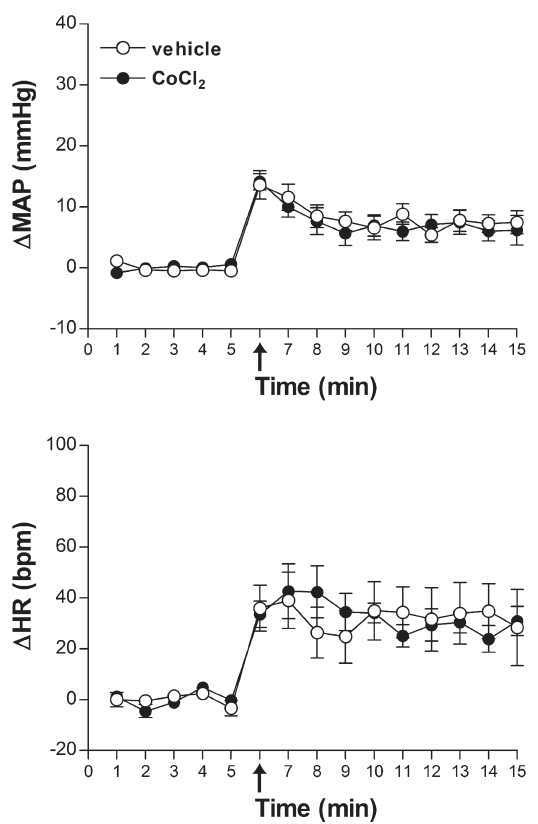

After Conditioning
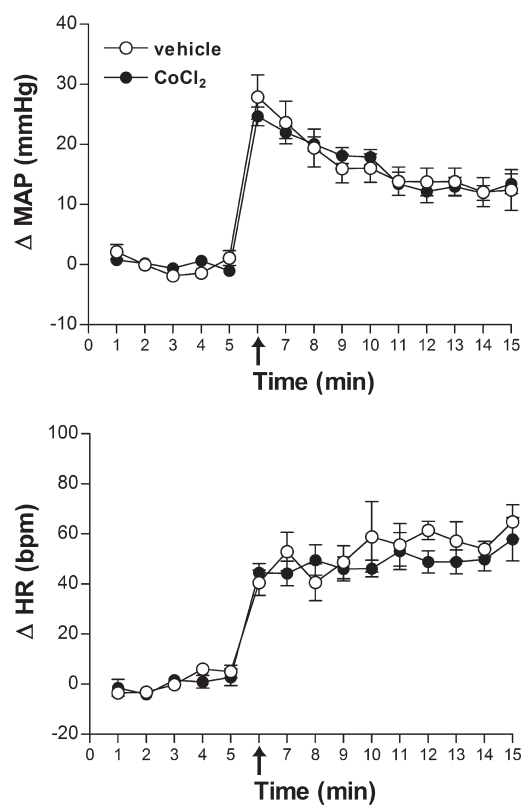

Before Test
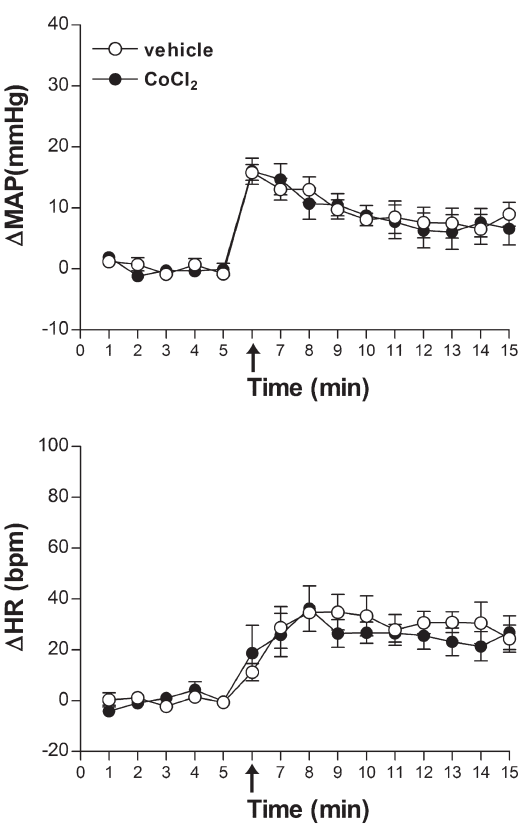

Before test
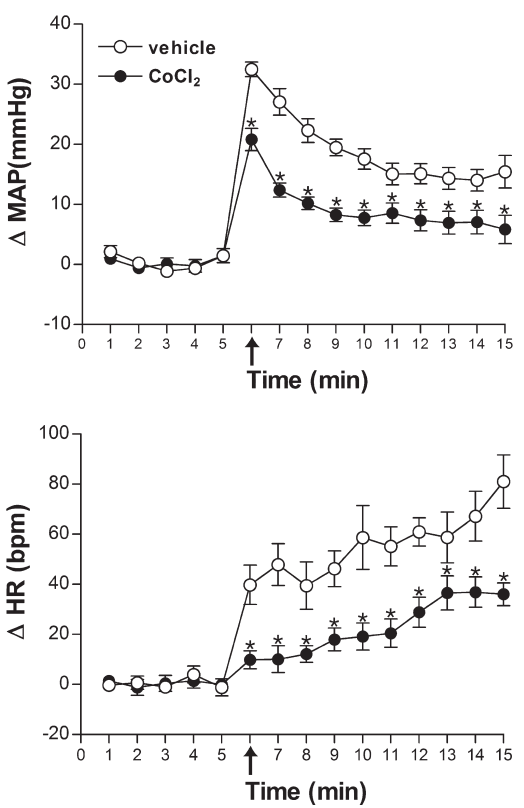

Figure 3. Time course of the effects of bilateral microinjection of $100 \mathrm{~nL}$ of vehicle or $1 \mathrm{nmol}$ of $\mathrm{CoCl}_{2}$ performed at three different treatment periods on mean arterial pressure $(\Delta \mathrm{MAP})$ and heart rate $(\Delta \mathrm{HR})$ in (top panel) nonconditioned $(n=5-6)$ and (bottom panel) conditioned animals $(n=5-7)$. Arrows indicate the start of the chamber re-exposure. Symbols represent the means, and bars the SEM. $(*) P<0.05$, Bonferroni's post-hoc test.

before or $10 \mathrm{~min}$ after the conditioning session, no interference in the expression of fear conditioning was found. These data suggest that synaptic neurotransmission in the LSA is involved in retrieval of the aversive context memory, but it is not implicated in acquisition or consolidation of aversive context memory. Because the treatment had no effect on nonconditioned rats, the results also indicate that the observed effects depend on a specific interaction with the fear conditioned response rather than nonspecific drug effects.
Irreversible lesions of the LSA have yielded contradictory results in animals exposed to aversive situations (Pesold and Treit 1992; Sparks and LeDoux 1995; Menard and Treit 1996; Sheehan et al. 2004). In contrast with our results, Sparks and LeDoux (1995) described that LSA electrolytic lesion performed $14 \mathrm{~d}$ before the conditioning session increased conditioned freezing behavior to context. However, in addition to including fibers of passage, the electrolytic lesions in their experiment are larger than ours, involving most parts of the septal area. Moreover, it 
has been shown that the emotional changes that follow brain lesions may vary as a function of time (Rangel et al. 2003). Social interaction, for example, increased $2 \mathrm{wk}$ after ventral medial prefrontal cortex (vMPFC) lesions, but decreased $5 \mathrm{wk}$ later, suggesting the involvement of secondary plastic changes (Rangel et al. 2003). In the present study, we overcame these problems by inducing an acute and reversible LSA inhibition with $\mathrm{CoCl}_{2}$ (Scopinho et al. 2007). This compound has been employed to induce reversible inhibition of specific brain structures (Pelosi et al. 2007; Crestani et al. 2008; Resstel et al. 2008a; Tavares et al. 2009). It causes a reversible synaptic inactivation that spreads over an area of $\sim 0.1-2 \mathrm{~mm}^{2}$. $\mathrm{CoCl}_{2}$ works by reducing $\mathrm{Ca}^{2+}$ pre-synaptic influx thus interfering with neurotransmitter release, causing a synaptic blockage without interfering with fibers of passage (Hagiwara and Byerly 1981; Lomber 1999). Thus, by causing temporary inactivation of local neurotransmission, the use of $\mathrm{CoCl}_{2}$ can minimize several problems associated with irreversible lesion techniques. Moreover, nonselective lesions of the LSA adjacent structures' medial septal area (MSA) and bed nucleus of the stria terminalis (BNST), which send projections to the hippocampus (Amaral and Kurz 1985; Everitt and Robbins 1997; Dong et al. 2001), produce profound deficits in spatial memory (Mizumori et al. 1990; Givens and Olton 1994; Everitt and Robbins 1997; Calandreau et al. 2007; Fitz et al. 2008). Therefore, the contradictory results observed after LSA irreversible lesions compared to the acute reversible synaptic blockage used in this study could be explained not only by the different functional impact of the experimental procedures, but also by a possible involvement of LSA adjacent structures.

Also different from the present results, acute LSA inhibition by local injection of lidocaine before a conditioning session was reported to reduce freezing in mice re-exposed to an aversive conditioned context (Calandreau et al. 2007). There are, however, important differences between this latter study and ours. In addition to the distinct species used, lidocaine also affects fibers of passage by blocking voltage-gated $\mathrm{Na}^{+}$channels (Lomber 1999). Moreover, in the previous study by Calandreau et al. (2007), a discrete stimulus (a tone) was included in the contextual fear conditioning session. Phillips and LeDoux (1994) showed that the dorsal hippocampus is engaged in the expression of contextual fear when a discrete cue is added to the context where the conditioning took place. In this situation the context is thought to predict the occurrence of the discrete cue (Phillips and LeDoux 1994).

The fimbria-fornix system is one of the main sources of afferent and efferent fibers of the hippocampal formation (Andersen et al. 1979). Despite some conflicting results, this system is proposed to play a key role in contextual fear response. Contextual fear deficits have been reported in rats with either fimbria-fornix or dorsal hippocampus lesions (Phillips and LeDoux 1995; Maren and Fanselow 1997). Electrophysiological studies have also suggested that the fimbria-LSA pathway is involved in this process. In mice, re-exposure to contextual conditioned stimuli has been associated with a decrease in synaptic transmission in the fimbria-LSA pathway. Moreover, tetanic fimbrial stimulationinduced long-term potentiation (LTP) in the lateral septum impaired the expression but not the acquisition of contextual fear conditioning (Vouimba et al. 1999). Low-frequency stimulation of this pathway, however, suppressed the impairing effect of tetanus on contextual conditioning and enhanced freezing to contextual stimuli. It was suggested that the level of hippocampal-septal neurotransmission and the magnitude of freezing would be related whenever the situation offered no possibility to predict and/or to avoid the aversive event (Vouimba et al. 1999).

The LSA role in organizing physiological, in addition to behavioral, components of defensive responses suggests its association with integrative centers controlling autonomic functions (Whitehead et al. 2000). In fact, the LSA has reciprocal connections with the central nuclei of the amygdala and receives projections from the hippocampus (Volz et al. 1990; Sheehan et al. 2004), the vMPFC (Vertes 2004), and BNST (Risold and Swanson 1997), brain areas with an established role in behavior and cardiovascular responses associated with contextual fear conditioning (Kim and Fanselow 1992; Phillips and LeDoux 1992; Resstel et al. 2006a, 2008a,b,c). Our results show that LSA inhibition before testing attenuated not only the behavioral but also the cardiovascular changes associated with exposure to the aversive context. This finding corroborates a large number of studies indicating that the LSA can modulate cardiovascular activity (Scopinho et al. 2006, 2007, 2008). Supporting this LSA role, it was described that its inactivation reduced the cardiovascular response observed in rats during acute restraint stress (Kubo et al. 2002) and the baroreflex activity in normotensive unanesthetized rats (Scopinho et al. 2007). Several neurotransmitter systems seem to be involved in these effects. Local LSA administration of noradrenergic and cholinergic receptor agonists increases blood pressure, whereas glutamate agonists cause vasodilatation of hindlimbs. Both responses are observed during stress situations. Direct injection of GABA agonists into the LSA, on the other hand, reduces the cardiovascular responses associated with defensive behavior (Peres-Polon and Corrês et al. 1992; Kubo et al. 2002; Scopinho et al. 2006).

In conclusion, the present results indicate that the LSA could play an important role in the expression of fear conditioning, modulating both the behavioral and cardiovascular responses induced by re-exposure to the aversively conditioned context. They also suggest that this region is not essential for the acquisition and consolidation of contextual fear conditioning.

\section{Acknowledgments}

D.G.R. is a FAPESP PhD fellow (2008/04069-7) and A.A.S. is a CAPES post-doctoral fellow (PNPD0176087). This work was supported by grants from the CNPq (305996/2008-8 and 480550/ 2007-7), FAPESP, and FAEPA.

\section{References}

Amaral DG, Kurz J. 1985. An analysis of the origins of the cholinergic and noncholinergic septal projections to the hippocampal formation of the rat. J Comp Neurol 240: 37-59.

Andersen P, Bland HB, Myhrer T, Schwartzkroin PA. 1979.

Septo-hippocampal pathway necessary for dentate theta production. Brain Res 165: 13-22.

Beck CH, Fibiger HC. 1995. Conditioned fear-induced changes in behavior and in the expression of the immediate early gene c-fos: With and without diazepam pretreatment. J Neurosci 15: 709-720.

Blanchard RJ, Blanchard DC. 1969. Passive and active reactions to fear-eliciting stimuli. J Comp Physiol Psychol 68: 129-135.

Calandreau L, Jaffard R, Desmedt A. 2007. Dissociated roles for the lateral and medial septum in elemental and contextual fear conditioning. Learn Mem 14: 422-429.

Covian MR. 1966. Physiology of the septal area. Acta Physiol Lat Am 16: 119-152.

Crestani CC, Tavares RF, Alves FH, Resstel LB, Correa FM. 2008. Diagonal band of Broca modulates the cardiac component of the baroreflex in unanesthetized rats. Neurosci Lett 448: 189-193.

Dong HW, Petrovich GD, Watts AG, Swanson LW. 2001. Basic organization of projections from the oval and fusiform nuclei of the bed nuclei of the stria terminalis in adult rat brain. J Comp Neurol 436: 430-455.

Duncan GE, Johnson KB, Breese GR. 1993. Topographic patterns of brain activity in response to swim stress: Assessment by 2-deoxyglucose uptake and expression of Fos-like immunoreactivity. J Neurosci 13: 3932-3943.

Everitt BJ, Robbins TW. 1997. Central cholinergic systems and cognition. Annu Rev Psychol 48: 649-684.

Fanselow MS. 1980. Conditioned and unconditional components of post-shock freezing. Pavlov J Biol Sci 15: 177-182. 
Fanselow MS. 2000. Contextual fear, gestalt memories, and the hippocampus. Behav Brain Res 110: $73-81$.

Fitz NF, Gibbs RB, Johnson DA. 2008. Selective lesion of septal cholinergic neurons in rats impairs acquisition of a delayed matching to position T-maze task by delaying the shift from a response to a place strategy. Brain Res Bull 77: 356-360.

Givens B, Olton DS. 1994. Local modulation of basal forebrain: Effects on working and reference memory. J Neurosci 14: 3578-3587.

Hagiwara S, Byerly L. 1981. Calcium channel. Annu Rev Neurosci 4: 69-125.

Kim JJ, Fanselow MS. 1992. Modality-specific retrograde amnesia of fear. Science 256: 675-677.

Kubo T, Kanaya T, Numakura H, Okajima H, Hagiwara Y, Fukumori R. 2002. The lateral septal area is involved in mediation of immobilization stress-induced blood pressure increase in rats. Neurosci Lett 318: 25-28.

Kuniecki M, Coenen AM, Kaiser J. 2002. Correlation between long latency evoked potentials from amygdala and evoked cardiac response to fear conditioned stimulus in rats. Acta Neurobiol Exp (Wars) 62: $85-92$.

LeDoux JE, Iwata J, Cicchetti P, Reis DJ. 1988. Different projections of the central amygdaloid nucleus mediate autonomic and behavioral correlates of conditioned fear. J Neurosci 8: 2517-2529.

Lomber SG. 1999. The advantages and limitations of permanent or reversible deactivation techniques in the assessment of neural function. J Neurosci Methods 86: 109-117.

Maren S, Fanselow MS. 1997. Electrolytic lesions of the fimbria/fornix, dorsal hippocampus, or entorhinal cortex produce anterograde deficits in contextual fear conditioning in rats. Neurobiol Learn Mem 67: $142-149$.

Menard J, Treit D. 1996. Lateral and medial septal lesions reduce anxiety in the plus-maze and probe-burying tests. Physiol Behav 60: 845-853.

Mizumori SJ, Perez GM, Alvarado MC, Barnes CA, McNaughton BL. 1990. Reversible inactivation of the medial septum differentially affects two forms of learning in rats. Brain Res 528: 12-20.

Paxinos G. 1995. The rat nervous system, 2nd ed. Academic Press, New York.

Paxinos G, Watson C. 1997. The rat brain in stereotaxic coordinates, 4 th ed. Academic Press, San Diego, CA.

Pelosi GG, Resstel LB, Correa FM. 2007. Dorsal periaqueductal gray area synapses modulate baroreflex in unanesthetized rats. Auton Neurosci 131: $70-76$.

Peres-Polon VL, Correa FM. 1992. Pressor effects of acetylcholine microinjected into forebrain nuclei of unanesthetized rats. Braz J Med Biol Res 25: 257-266.

Pesold C, Treit D. 1992. Excitotoxic lesions of the septum produce anxiolytic effects in the elevated plus-maze and the shock-probe burying tests. Physiol Behav 52: 37-47.

Pezzone MA, Lee WS, Hoffman GE, Rabin BS. 1992. Induction of c-Fos immunoreactivity in the rat forebrain by conditioned and unconditioned aversive stimuli. Brain Res 597: 41-50.

Phillips RG, LeDoux JE. 1992. Differential contribution of amygdala and hippocampus to cued and contextual fear conditioning. Behav Neurosci 106: $274-285$

Phillips RG, LeDoux JE. 1994. Lesions of the dorsal hippocampal formation interfere with background but not foreground contextual fear conditioning. Learn Mem 1: 34-44.

Phillips RG, LeDoux JE. 1995. Lesions of the fornix but not the entorhinal or perirhinal cortex interfere with contextual fear conditioning. $J$ Neurosci 15: 5308-5315.

Rangel A, Gonzalez LE, Villarroel V, Hernandez L. 2003. Anxiolysis followed by anxiogenesis relates to coping and corticosterone after medial prefrontal cortical damage in rats. Brain Res 992: 96-103.

Resstel LB, Joca SR, Guimaraes FG, Correa FM. 2006a. Involvement of medial prefrontal cortex neurons in behavioral and cardiovascular responses to contextual fear conditioning. Neuroscience 143: 377-385.
Resstel LB, Joca SR, Moreira FA, Correa FM, Guimaraes FS. 2006b. Effects of cannabidiol and diazepam on behavioral and cardiovascular responses induced by contextual conditioned fear in rats. Behav Brain Res 172: 294-298.

Resstel LB, Alves FH, Reis DG, Crestani CC, Correa FM, Guimaraes FS. 2008a. Anxiolytic-like effects induced by acute reversible inactivation of the bed nucleus of stria terminalis. Neuroscience 154: 869-876.

Resstel LB, Correa FM, Guimaraes FS. 2008b. The expression of contextual fear conditioning involves activation of an NMDA receptor-nitric oxide pathway in the medial prefrontal cortex. Cereb Cortex 18: 2027-2035.

Resstel LB, Joca SR, Correa FM, Guimaraes FS. 2008c. Effects of reversible inactivation of the dorsal hippocampus on the behavioral and cardiovascular responses to an aversive conditioned context. Behav Pharmacol 19: 137-144.

Resstel LB, Lisboa SF, Aguiar DC, Correa FM, Guimaraes FS. 2008d. Activation of CB1 cannabinoid receptors in the dorsolateral periaqueductal gray reduces the expression of contextual fear conditioning in rats. Psychopharmacology (Berl) 198: 405-411.

Risold PY, Swanson LW. 1997. Chemoarchitecture of the rat lateral septal nucleus. Brain Res Brain Res Rev 24: 91-113.

Scopinho AA, Resstel LB, Antunes-Rodrigues J, Correa FM. 2006. Pressor effects of noradrenaline injected into the lateral septal area of unanesthetized rats. Brain Res 1122: 126-134.

Scopinho AA, Crestani CC, Alves FH, Resstel LB, Correa FM. 2007. The lateral septal area modulates the baroreflex in unanesthetized rats. Auton Neurosci 137: 77-83.

Scopinho AA, Tavares RF, Busnardo C, Correa FM. 2008. Non- $N$-methyl-D-aspartate glutamate receptors in the paraventricular nucleus of hypothalamus mediate the pressor response evoked by noradrenaline microinjected into the lateral septal area in rats. J Neurosci Res 86: 3203-3211.

Sheehan TP, Chambers RA, Russell DS. 2004. Regulation of affect by the lateral septum: Implications for neuropsychiatry. Brain Res Brain Res Rev 46: $71-117$.

Sparks PD, LeDoux JE. 1995. Septal lesions potentiate freezing behavior to contextual but not to phasic conditioned stimuli in rats. Behav Neurosci 109: $184-188$.

Swanson LW, Cowan WM. 1977. An autoradiographic study of the organization of the efferent connections of the hippocampal formation in the rat. J Comp Neurol 172: 49-84.

Tavares RF, Correa FM. 2006. Role of the medial prefrontal cortex in cardiovascular responses to acute restraint in rats. Neuroscience 143: $231-240$.

Tavares RF, Correa FM, Resstel LB. 2009. Opposite role of infralimbic and prelimbic cortex in the tachycardiac response evoked by acute restraint stress in rats. J Neurosci Res 87: 2601-2607.

Vertes RP. 2004. Differential projections of the infralimbic and prelimbic cortex in the rat. Synapse 51: $32-58$.

Volz HP, Rehbein G, Triepel J, Knuepfer MM, Stumpf H, Stock G. 1990. Afferent connections of the nucleus centralis amygdalae. A horseradish peroxidase study and literature survey. Anat Embryol (Berl) 181: 177-194.

Vouimba RM, Garcia R, Jaffard R. 1999. Pretraining tetanic fimbrial stimulation impairs the expression but not the acquisition of contextual fear conditioning in mice. Neuroscience 93: 869-876.

Whitehead MC, Bergula A, Holliday K. 2000. Forebrain projections to the rostral nucleus of the solitary tract in the hamster. J Comp Neurol 422: 429-447.

Received July 7, 2009; accepted in revised form December 7, 2009. 


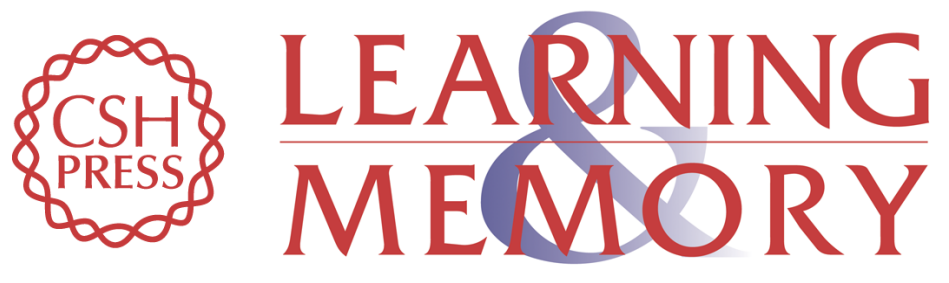

\section{Involvement of the lateral septal area in the expression of fear conditioning to context}

Daniel G. Reis, América A. Scopinho, Francisco S. Guimarães, et al.

Learn. Mem. 2010, 17:

Access the most recent version at doi:10.1101//m.1534710

References This article cites 50 articles, 8 of which can be accessed free at:

http://learnmem.cshlp.org/content/17/3/134.full.html\#ref-list-1

License

Email Alerting Receive free email alerts when new articles cite this article - sign up in the box at the Service top right corner of the article or click here. 